Available online on 15.03.2017 at $\mathrm{http}: / /$ jddtonline.info
Journal Of Drug Delivery and Therapeutics
Op11-17, publisher and licensee JDDT, This is an Open Access article which permits unrestricted
noncommercial use, provided the original work is properly cited

Research Article

\title{
EVALUATION OF CRYSTALLINE PENICILLIN UTILIZATION IN PEDIATRICS WARD OF TERTIARY CARE HOSPITAL OF EASTERN ETHIOPIA: THE CASE OF HIWOT FANA SPECIALIZED UNIVERSITY HOSPITAL
}

\author{
Jemal Abdela $^{1}$, Mekonnen Sisay ${ }^{*}$, Zenebe Kano ${ }^{2}$ \\ ${ }^{1}$ Department of Pharmacology, School of Pharmacy, College of Health and Medical Sciences, Haramaya University, Harar, Ethiopia \\ ${ }^{2}$ Clinical Pharmacy Unit, Hiwot Fana Specialized University Hospital, Harar, Ethiopia
}

\section{ABSTRACT}

Background: Crystalline penicillin is one of the commonly prescribed antibiotics used for the treatment of certain susceptible bacterial infections over several years in Ethiopia. However, little is known about the appropriateness of clinical indication, dose and frequency of administration, duration and therapeutic outcome of patients in general and pediatrics in particular. Therefore, the study aimed to evaluate the rational use of crystalline penicillin injection in pediatrics ward of Hiwot Fana Specialized University Hospital (HFSUH), Eastern Ethiopia.

Methods: Retrospective cross sectional study was employed for evaluating medication records of hospitalized pediatric patients who received crystalline penicillin from Dec 1, 2015- Feb 29, 2016 at pediatrics ward of HFSUH. Based on Joint Commission on Accreditation of Healthcare Organizations (JCAHCO) criteria, 114 medical records (20\%) were selected by systematic random sampling from the total of 570 records. The study was conducted from Mar 1-Mar 15, 2016. Besides, the data were evaluated against Standard treatment guideline (STG) of Ethiopia for general hospitals and World Health Organization (WHO) drug use evaluation guideline

Results: Among the 114 medical records of pediatric patients included in the study, the dose and frequency of administration, contra-indications and drug interactions of crystalline penicillin were according to the STG of Ethiopia for general hospitals, and WHO Guidelines for the management of common illnesses in children in areas with limited resources. All the 114 (100\%) cases were consistent with guidelines for contra-indications and drug interaction of crystalline penicillin use. Moreover, 108(94.74\%) and $112(98.24 \%)$ of the cases were in accordance with the guidelines for the dose and frequency of administration, respectively. However, $93(81.58 \%), 59(51.75 \%)$ and $59(51.75 \%)$ of the patient cases were not according to the guidelines of crystalline penicillin use for indications, duration and outcome of therapy, respectively.

Conclusion: Crystalline penicillin utilization pattern in pediatric ward of HFSUH has fully adhered to the STG of Ethiopia for general hospitals and WHO Guideline for the majority of the parameters with regard to dose and frequency of administration, contraindications, and drug interactions as well as met the thresholds set for most of the DUE criteria. However, indication, duration and outcome of therapy were not in accordance with the guideline.

Keywords: Drug use evaluation; Pediatrics; medication records; crystalline penicillin; Standard treatment Guidelines; World Health Organization

Article Info
Received Feb 14, 2017; Review Completed March 11, 2017; Accepted March 11, 2017; Available online March 15, 2017

Cite this article as:

Abdela J, Sisay M, Kano Z, Evaluation of crystalline penicillin utilization in pediatrics ward of tertiary care hospital of eastern Ethiopia: the case of Hiwot Fana Specialized University Hospital, Journal of Drug Delivery and Therapeutics. 2017; 7(2):62-69. DOI: http://dx.doi.org/10.22270/jddt.v7i2.1413

*Address for Correspondence

Mekonnen Sisay, School of Pharmacy, College of Health and Medical Sciences, Haramaya University, Harar, P.O.Box 235, Ethiopia Cell phone, +251920-21-21-35, Email: - mekonnensisay27@yahoo.com

Competing interests: The authors have declared that there is no competing interest

Funding: No specific grant for this study 


\section{INTRODUCTION}

DUE is a system of ongoing, systematic criteria based evaluation of drug use to ensure whether medicines are used properly at the individual patient level ${ }^{1}$. DUE may be applied to an individual drug, therapeutic categories, clinical condition (disease state), utilization process or therapeutic outcomes of drugs ${ }^{2}$. DUE can address the actual process of medication administration, prescribing, and dispensing activities. It involves a comprehensive review of patients' prescription and medication data before, during and after dispensing for ease of appropriate decision making and positive therapeutic outcome $^{3}$. If properly designed, DUE provides not only a means of identifying drug use problems but also a means to correct the problem and there by contribute to rational drug therapy ${ }^{4}$.

The potential inappropriate utilization of drugs has become a major global concern given increment in variety and quantity of pharmaceutical products. Potentially inappropriate use of medication is associated negative health impact to the patient and wastage of financial resources to the health facilities and the patients as well. Hence, numerous studies have tried to address this issue and designed strategies to probe and resolve the problem as well as to prevent it ${ }^{5}$.

Concerning the use of medicines in infants and children, there are certain unique set of challenges to the prescribers. It is obvious that safety, efficacy, pharmacokinetic and pharmacodynamic profile of medicines are influenced significantly by physiological variances between children and adults. However, most pharmacokinetic and pharmacodynamic studies provide little information on drug action in neonates, infants and children, due to exclusion of this age group in many experimental studies ${ }^{6}$. The 'Better Medicine for Children' slogan of 2007, World Health Assembly, recognized the need for research and development on childhood medicines including better dosage forms, better evidence and better information about how to ensure that medicines for treating the common childhood diseases are given at the right dose for children of all ages ${ }^{7}$.

The increased prevalence of known resistant organisms and the emergence of newly resistant organisms have resulted in prolonging the treatment and length hospitalization, which in turn results in increased direct and indirect healthcare costs to the patients. Therefore, evaluation of antimicrobial use is essential for checking whether the appropriate usages of antimicrobial agents are present ${ }^{8}$. An improvement of resistances can be achieved by temporary reduction of the use of the respective categories of antibiotics ${ }^{9}$.

DUE is one of the methods used in combating the development of bacterial resistant to anti-microbial agents and improving therapy. DUE is a performance improvement method that focuses on evaluating and improving drug use processes to achieve optimal patient outcomes 10, 11. DUE is of three types; prospective, concurrent and retrospective. A retrospective DUE is the simplest to perform since drugs therapy is reviewed after patient has received the medication. A retrospective review may detect patterns in prescribing, dispensing or administering drugs to prevent recurrence of inappropriate use and serves as a means for developing prospective standards and target interventions ${ }^{1,12}$. Thus, the aim of the study was to evaluate the utilization of crystalline penicillin injection in pediatrics ward of HFSUH.

\section{METHODS}

\section{Study area and period}

Harar is located $526 \mathrm{Km}$ away from Addis Ababa to the east. Harari Region is one of the nine National Regional States of Ethiopia, with the town of Harar as its capital. Based on the 2007 Census result of the CSA, Harari has a total population of 183,344 , of which 92,258 were male and 91,086 female; 99,321 or $54.17 \%$ of the population were urban inhabitants. In the region, there are 4 governmental hospitals, $1 \mathrm{NGO}$ and 2 private hospitals, and 8 health centers ${ }^{13}$. Among the governmental hospitals, this study was conducted in pediatric wards of HFSUH from March 1-15, 2016 G.C.

\section{Study design}

Hospital based retrospective cross-sectional study design was employed to evaluate utilization pattern of crystalline penicillin in pediatric ward of HFSUH in the study period.

\section{Population}

All pediatric patient medication records containing crystalline penicillin in HFSUH was used as a source population for this study. Medication records with crystalline penicillin use for the specified three months (quarter of a year) (Dec 1, 2015-Feb 29, 2016) was considered as study population from which sampling units were drawn.

\section{Sample size determination and sampling technique}

According to the Joint Commission on Accreditation of Healthcare Organizations (JCAHCO) criteria which mandates: - if the average number of cases per quarter is more than 600, at least $5 \%$ cases are reviewed; if the number of cases per quarter is fewer than 600, at least 30 cases are reviewed and if there are fewer than 30 cases per quarter, then $100 \%$ of the cases are reviewed ${ }^{14}$. Based on these criteria, patient medication records containing crystalline penicillin and targeting pediatric patients was considered retrospectively for a quarter (Dec 1, 2015-Feb 29, 2016). From the study which encompassed data of three month crystalline penicillin use in pediatric ward, the number of cases (crystalline penicillin indication) per quarter was found to be 570 . Therefore, to obtain greater point estimate of population, about $114(20 \%)$ medication records were taken as the final sample size which is much greater than the minimum sample size $(n=30)$ as per JCAHCO recommendation.

Once the sample size had been determined for the study, systematic random sampling was employed to obtain sample population. Sampling frame was prepared by coding 570 medication records according to the chronological order (date of records) and sampling interval was calculated as follows 


\section{Abdela et al}

$\mathrm{K}=$ study population/calculated sample size $=570 / 114=\underline{\mathbf{5}}$

Once the first sample was randomly selected, all the rest samples were taken by picking every $5^{\text {th }}$ of the medical record until the aforementioned sample size was obtained

\section{Variables}

\section{Dependent variables}

Drug use evaluation of crystalline penicillin

\section{Independent variable}

Variables including socio-demographic characteristics of pediatric patients (age, sex), clinical characteristics (comorbidity, nature and severity of infection, underlying medical conditions, nature of diagnosis and treatment modalities, prevalence of infections) etc are among the factors that ultimately affect utilization pattern of crystalline penicillin in the pediatric ward.

Data collection instrument and techniques

After all preliminary preparations were completed for data collection; data were collected retrospectively using structured observational check list (data abstraction
Journal of Drug Delivery \& Therapeutics. 2017; 7(2):62-69

format) from medication records of pediatric patients during the study period.

\section{Data quality control}

Pre testing was done to check whether the data collection format was valid and reliable. The data were checked and cleared every day for ensuring completeness and consistency before undergoing data processing and analysis.

\section{Data processing and analysis}

The collected data were entered and processed using SPSS v21 (SPSS Inc., Chicago, IL, USA). Besides, the data were evaluated against Standard treatment guideline (STG) of Ethiopia for general hospitals and WHO DUE guideline. As there is no STG for teaching and referral hospitals, drug use evaluation criteria with thresholds was set based on the national STG of Ethiopia for general hospitals, WHO guide for DUE and WHO Guidelines for the management of common illnesses in children in areas where limited resources are highly noticeable ${ }^{4,15,16}$. The DUE criteria for crystalline penicillin utilization was presented below (Table 1)

Table 1: Drug use evaluation criteria for crystalline penicillin.

\begin{tabular}{|c|c|c|}
\hline Indicator & Criteria & Threshold \\
\hline Indication & $\begin{array}{l}\text { Severe Pneumonia } \\
\text { Pyogenic meningitis (Meningococcal meningitis and Pneumococcal meningitis) } \\
\text { Generalized Neonatal tetanus } \\
\text { Congenital syphilis } \\
\text { Neonatal sepsis } \\
\text { Cellulites } \\
\text { Erysipelas } \\
\text { Endocarditis }\end{array}$ & 100 \\
\hline $\begin{array}{l}\text { Dose and dose } \\
\text { frequency }\end{array}$ & $\begin{array}{l}\text { Bacteremia: } 25,000 \text { to } 50,000 \text { units/kg/dose IV infusion over } 30 \text { minutes, or IM } \\
\text { Severe Pneumonia: } 50,000 \text { units/kg/24 hours IV QID } \\
\text { Meningococcal meningitis: } 250,000 \text { units/kg/dose IV infusion over } 30 \text { minutes, or IM } \\
\text { every } 4 \text { hour } \\
\text { Pneumococcal meningitis: } 250,000 \text { units/kg/dose IV infusion over } 30 \text { minutes, or IM } \\
\text { every } 4 \text { hour } \\
\text { Neonatal sepsis: } 50,000 \mathrm{IU} / \mathrm{kg} / 24 \text { hours IV QID } \\
\text { Neonatal tetanus: } 50,000 \mathrm{IU} / \mathrm{kg} / 24 \text { hours IV QID } \\
\text { Cellulites: } 50,000 \mathrm{IU} / \mathrm{kg} / 24 \mathrm{hours} \text { IV } 4 \text { hourly } \\
\text { Erysipelas: } 50,000 \mathrm{IU} / \mathrm{kg} / 24 \mathrm{hours} \text { IV } \\
\text { Prevention of Bacterial Endocarditis: } 50,000 \text { IU/kg intravenously or intramuscularly } \\
30 \text { to } 60 \text { minutes before the } \\
\text { procedure and, } 1 \text { million IU ( } 25,000 \text { IU } / \mathrm{kg} \text { for children) six hours later } \\
\text { Gonococcus infection (only with proven penicillin-susceptible isolate): } 100,000 \\
\text { units/kg/dose IV infusion over } 30 \\
\text { minutes, or IM } \\
\text { Congenital syphilis: } 50,000 \text { units/kg/dose IV over } 30 \text { minutes, given Q } 12 \text { hours during } \\
\text { the first } 7 \text { days of life }\end{array}$ & 95 \\
\hline Duration & $\begin{array}{l}\text { Congenital syphilis: } 10-14 \text { days } \\
\text { Severe Pneumonia: } 3 \text { days } \\
\text { Meningococcal meningitis: } 10 \text { days } \\
\text { Pneumococcal meningitis: } 7 \text { days } \\
\text { Neonatal sepsis: } 10 \text { days } \\
\text { Neonatal tetanus: } 10 \text { days } \\
\text { Cellulites: } 10 \text { days } \\
\text { Erysipelas: until the fever subside } \\
\text { Endocarditis: } 2-6 \text { weeks }\end{array}$ & 90 \\
\hline
\end{tabular}




\begin{tabular}{|l|l|c|} 
Abdela et al & \multicolumn{1}{|c|}{ Journal of Drug Delivery \& Therapeutics. 2017; 7(2):62-69 } \\
\hline $\begin{array}{l}\text { Contra- } \\
\text { indications }\end{array}$ & Penicillin hypersensitivity reaction; avoid intrathecal route & 100 \\
\hline $\begin{array}{l}\text { Drug } \\
\text { interactions }\end{array}$ & $\begin{array}{l}\text { Methotrexate, } \\
\text { - Probenecid (decrease renal tubular secretion of the penicillin's), } \\
\text {-Aminoglycosides (inactivated by high doses of IV benzyl penicillin; should not be } \\
\text { administered in same IV set. }\end{array}$ & 90 \\
\hline Outcome & $\begin{array}{l}\text { Fever reduction } \\
\text { Decrease of at least } 1^{\circ} \mathrm{C} \text { from peak temperature within 3 days of initial crystalline } \\
\text { penicillin dose } \\
\text { Fever not present initially } \\
\text { Clinical improvement noted in progress } \\
\text { New organism or another infection suspected or identified } \\
\text { Patient discharged before therapy completed and unavailable for follow-up } \\
\text { Patient expired \& Switch to oral therapy }\end{array}$ & 95 \\
\hline
\end{tabular}

\section{RESULTS}

Socio demographic characteristics

In this drug use evaluation study, as per JCAHCO recommendation, a total of 114 medical records containing crystalline penicillin injection and targeting pediatric patients at HFSUH was evaluated for their therapeutic appropriateness. From these cards, the majority of patients were found to be male $61(53.51 \%)$ and the majority of age group falls under 1-5 years 57 $(50.00 \%)($ Table-2)

Table 2: Age-sex distribution of pediatric patients at the HFSUH pediatric ward from Dec 1, 2015- Feb 29, 2016.

\begin{tabular}{|l|l|l|l|}
\hline Socio-demographic characteristics & Frequency & $\%$ \\
\hline \multirow{3}{*}{ Gender } & Female & 53 & 46.49 \\
\cline { 2 - 4 } & Male & 61 & 53.51 \\
\hline \multirow{4}{*}{ Age } & $<1$ month (neonate) & - & - \\
\cline { 2 - 4 } & $1-12$ month (infant) & 46 & 40.35 \\
\cline { 2 - 4 } & $1-5$ years & 57 & 50.00 \\
\cline { 2 - 4 } & $6-10$ & 5 & 4.39 \\
\cline { 2 - 4 } & $>10$ years & 6 & 5.56 \\
\hline
\end{tabular}

Modalities of crystalline penicillin use, appropriateness of indication and dosage

Out of the pediatric medical records reviewed, the predominant use of crystalline penicillin was for empirical treatment which accounts 70(61.41\%), followed by definitive treatment with the evidence of laboratory diagnosis in case of $44(38.59 \%)$ patients; however, no data were registered for prophylactic use. Besides, out of the total records, 93 (81.58\%) medication records contain correct indication of crystalline penicillin according to the guideline whereas, 108 $(94.74 \%)$ patient medication records contain correct dose of crystalline penicillin (Table 3 ).

Table 3: therapeutic modalities, appropriateness of indication and doses of crystalline penicillin at pediatric wards of HFSUH from Dec1, 2015-Feb 29, $2016(n=114)$

\begin{tabular}{|l|l|l|l|}
\hline \multicolumn{2}{|l|}{ Study parameters } & frequency & $\%$ \\
\hline \multirow{4}{*}{ Ways of therapy } & Empirical therapy & 70 & 61.41 \\
\cline { 2 - 4 } & Definitive therapy & 44 & 38.59 \\
\cline { 2 - 4 } & Prophylactic therapy & --- & -- \\
\hline \multirow{2}{*}{ Indication } & Correctly indicated & 93 & 81.58 \\
\cline { 2 - 4 } & Not correctly indicated & 21 & 18.42 \\
\hline \multirow{2}{*}{ Dose } & Correct dose & 108 & 94.74 \\
\cline { 2 - 4 } & Incorrect dose & 6 & 5.26 \\
\hline
\end{tabular}

Disease state for which crystalline penicillin was indicated

Based on the data on table 3, $93(81.58 \%)$ medical records contain crystalline penicillin with appropriate indications including severe pneumonia 70 (75.27\%), community acquired pneumonia $11(11.83 \%)$, congenital syphilis and HADD, each $6(6.45 \%)$ and these are the common diseases to which crystalline penicillin was prescribed in the study setting. Apart from this, 


\section{Abdela et al}

indications of crystalline penicillin for some disease were not concordant with STG of Ethiopia and DUE guideline of the WHO. The incorrect indications include
Journal of Drug Delivery \& Therapeutics. 2017; 7(2):62-69

recurrent severe pneumonia 7 (30\%), acute gastroenteritis and pertusis each account 4 (19.04\%) (Table-4).

Table 4: Disease state for which crystalline penicillin was indicated at pediatric ward of HFSUH from Dec 1, 2015- Feb $29,2016(\mathrm{n}=114)$

\begin{tabular}{|l|l|l|l|}
\hline \multicolumn{2}{|l|}{ Indications } & Frequency & $\%$ \\
\hline \multirow{3}{*}{$\begin{array}{l}\text { Correct indications } \\
(\mathrm{n}=93)\end{array}$} & Severe pneumonia & 70 & 75.27 \\
\cline { 2 - 4 } & Community acquired pneumonia & 11 & 11.83 \\
\cline { 2 - 4 } & Congenital syphilis & 6 & 6.45 \\
\cline { 2 - 4 } & HAAD & 6 & 6.45 \\
\hline \multirow{3}{*}{$\begin{array}{l}\text { Incorrect indications } \\
\text { (n=21) }\end{array}$} & Recurrent severe pneumonia & 7 & 30.00 \\
\cline { 2 - 4 } & Acute gastro enteritis & 4 & 19.04 \\
\cline { 2 - 4 } & Pertusis & 4 & 19.04 \\
\cline { 2 - 4 } & Ascites with hypertension II & 2 & ----- \\
\cline { 2 - 3 } & Chicken pox & 2 & ----- \\
\cline { 2 - 3 } & Typhus & 2 & ----- \\
\hline
\end{tabular}

\section{Frequency at crystalline penicillin given}

Given the indication, about $98.14 \%$ records were found to be correct frequency of administration (i.e. 4 times $(12.96 \%)$ and 6 times $(85.16 \%)$ ) while $1.85 \%$ is not correct. The most common frequency of administration of crystalline penicillin injection was found to six times daily (Figure 1).

\section{Duration at crystalline penicillin given}

Coming to the duration of treatment with crystalline penicillin injection, the most common duration of therapy was found to be five days and above (23.68\%) followed by two and three days (18.42\% each) (Table $5)$.

Table 5: Duration of therapy for the crystalline penicillin injection at pediatric wards of HFSUH from Dec 1, 2015- Feb 29, $2016(\mathrm{n}=114)$

\begin{tabular}{|l|l|l|}
\hline Duration of therapy (day) & Frequency & $\%$ \\
\hline Unspecified & 15 & 13.16 \\
\hline One & 19 & 16.67 \\
\hline Two & 21 & 18.42 \\
\hline Three & 21 & 18.42 \\
\hline Four & 11 & 9.65 \\
\hline Five and above & 27 & 23.68 \\
\hline Total & 114 & 100 \\
\hline
\end{tabular}

\section{Status of laboratory diagnosis}

In this study, the top laboratory diagnosis done for pediatric patients were complete blood count (CBC) with WBC differential 51 (44.74\%), blood film 25(21.93\%), X-ray 15(13.16\%) and $\mathrm{Hgb} 11(9.65 \%)$ (Table-6).

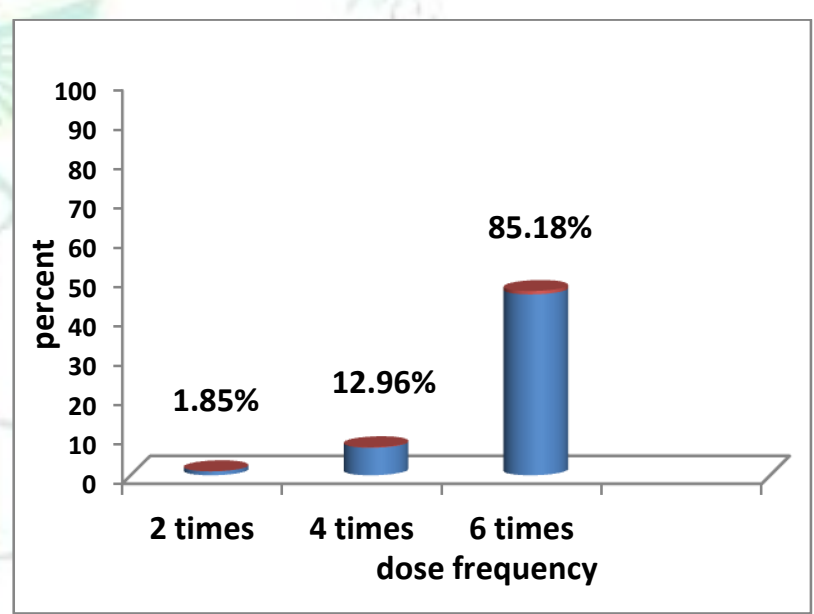

Figure 1: Frequency of crystalline penicillin injection per day at pediatric wards of HFSUH

Table 6: Presence of laboratory-diagnosis justifying involvement of susceptible strain at pediatric wards of HFSUH from Dec 1, 2015- Feb 29, $2016(n=114)$

\begin{tabular}{|l|l|l|l|l|}
\hline \multirow{2}{*}{ Type of laboratory tests } & \multirow{2}{*}{ Frequency } & \multicolumn{2}{|c|}{ Results } & \multirow{2}{*}{$\%$} \\
\cline { 3 - 5 } & & +ve & \\
\hline White blood cell & 51 & 21 & 30 & $44.74 \%$ \\
\hline Blood film & 25 & - & 25 & $21.93 \%$ \\
\hline X-ray & 15 & 4 & 11 & $13.16 \%$ \\
\hline Hgb & 11 & 7 & 4 & $9.65 \%$ \\
\hline ESR & 6 & 4 & 2 & $5.26 \%$ \\
\hline Stool analysis & 2 & 2 & -- & $1.75 \%$ \\
\hline WIDAL(ww) & 2 & 2 & -- & $1.75 \%$ \\
\hline Wieflex(wwf) & 2 & 2 & -- & $1.75 \%$ \\
\hline
\end{tabular}

$\mathrm{ESR}=$ erythrocyte sedimentation rate; $\mathrm{Hgb}=$ Haemoglobin 


\section{Co-administered drugs with crystalline penicillin}

About $87.04 \%$ crystalline penicillin charts contain co-administered drugs without any noticeable drug interactions observed. However, the rest (12.96\%) medical records contain crystalline penicillin only (Figure 2).

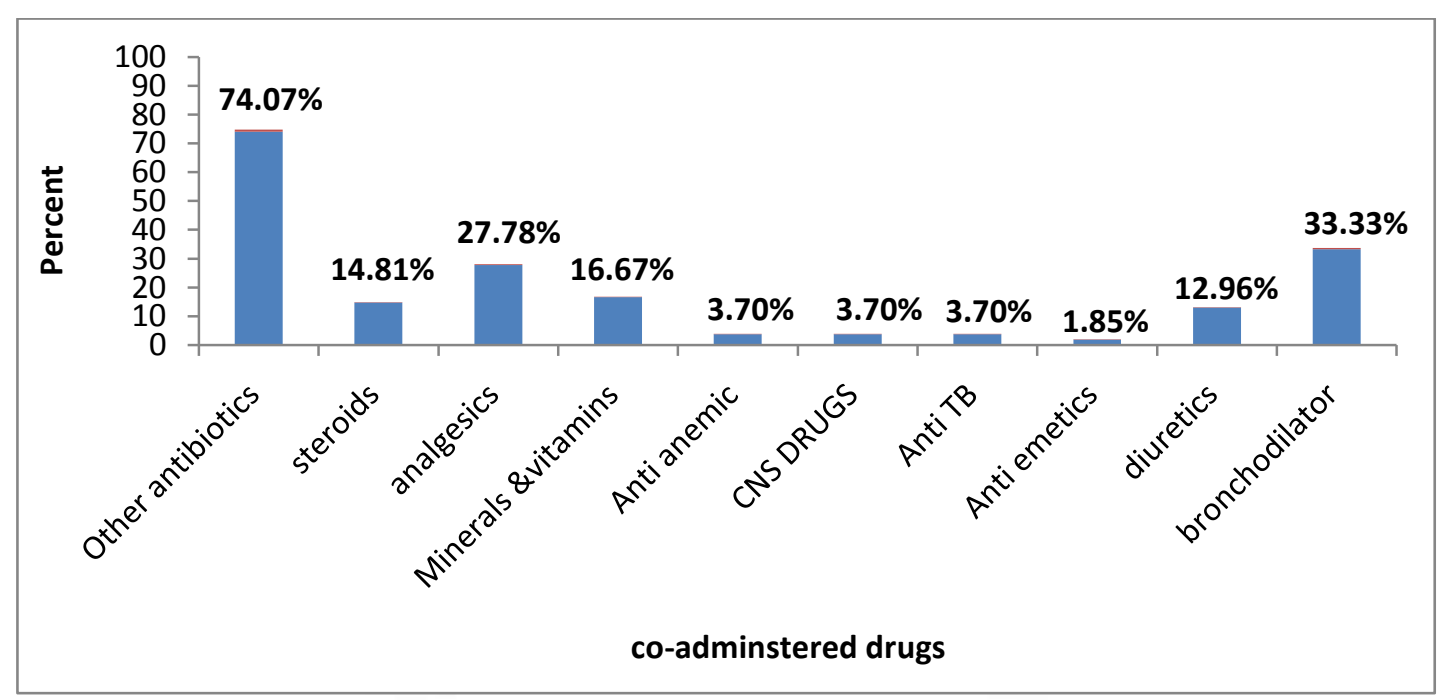

Figure 2: Co-administered drugs with crystalline penicillin at pediatric ward from Dec 1, 2015- Feb 29, 2016 (n=114)

\section{Patient outcomes measurements}

According to this study, from the total of 114 pediatric patient charts reviewed, about $59(51.75 \%)$ patients improved, $36(31.58 \%)$ patient outcomes not specified, $11(9.65 \%)$ patients self-discharged, and $8(7.4 \%)$ patients expired (Table 7).

Table 7: The observed outcomes of pediatric patients at HFSUH from Dec 1, 2015- Feb 29, 2016 (n=114)

\begin{tabular}{|l|l|c|}
\hline Final out comes & Frequency & $\%$ \\
\hline Improved & 59 & $51.75 \%$ \\
\hline Unspecified & 36 & $31.58 \%$ \\
\hline Self- discharged & 11 & $9.65 \%$ \\
\hline Expired (dead) & 8 & $7.02 \%$ \\
\hline Total & 114 & $100 \%$ \\
\hline
\end{tabular}

Table 8: Evaluation of overall DUE indicators against the threshold value

\begin{tabular}{|l|l|l|}
\hline Criteria & $\begin{array}{l}\text { Observed } \\
(\%)\end{array}$ & $\begin{array}{l}\text { Threshold } \\
(\%)\end{array}$ \\
\hline Indication & 81.58 & 100 \\
\hline $\begin{array}{l}\text { Dose \& dose frequency } \\
\text { (average) }\end{array}$ & 96.29 & 95 \\
\hline Duration & 51.75 & 90 \\
\hline Contra-indications (absence) & 100 & 100 \\
\hline Drug interactions (absence) & 100 & 90 \\
\hline Outcome & 51.75 & 95 \\
\hline
\end{tabular}

Coming to the overall assessment of crystalline penicillin utilization, promising results were obtained in cases of dose and frequency of administration, contraindication, and drug-drug interactions. However, when the observed data were compared to the threshold value, clinically sound deviation was observed in cases of indication, duration and outcome of crystalline penicillin therapy (Table 8).

\section{DISCUSSION}

The ultimate objective of DUE is to ensure that drugs are used in safe, economically viable, cost-effective approach in order to improve the therapeutic outcome of patients. Besides, with the aid of DUE, progressive improvement in the utilization pattern of drugs have several positive impacts on the healthcare delivery including lowering the healthcare cost to the individual patient and to the facility, reducing adverse drug reactions and drug interaction, improving patient adherence and maximizing therapeutic outcomes ${ }^{4,5}$.

Antibiotic stewardship programs should be designed to optimize treatment and make sure that patients receive antibiotics promptly and only when needed. They make sure that patients receive the right antibiotic at the right dose and for the right length of time, improving prescribing in hospitals and long-term care facilities, saving money, and saving lives ${ }^{17}$. The implementation of antibiotic guidelines or protocols has been shown to be a formal means of achieving the goals of appropriate antibiotic utilization, limiting unnecessary antibiotic use and, as a result, improving antibiotic susceptibility profiles ${ }^{18}$.

Successes of therapy largely relies on the knowledge of the physicians to diagnose the disease, select the right drugs, dose, dosage form and routes of administration, and without probable or suspected adverse reactions, drug interactions, and unnecessary duplication of therapy. Developing and applying hospital based drug formulary and STGs can be considered as a basis for promoting rational drug use. Drugs have to be prescribed (indicated) appropriately on the basis of clinical diseases identified through diagnosis. Hence, prescribers should stick with STGs while prescribing any drug ${ }^{4,16}$.

In this finding, 114 medication records which contain crystalline penicillin were taken from pediatric wards. Regarding to the indications of crystalline penicillin, the 
study indicated that $81.58 \%$ of the indications were appropriate as per the STG, and this was found less performance as compared with the threshold set for indication of crystalline penicillin $(100 \%){ }^{4,15,16}$. This result is lower than the study conducted in Jimma University specialized hospital in pediatric ward where $100 \%$ crystalline penicillin uses were found to be appropriate $^{19}$.

Coming to the dose of crystalline penicillin, different doses are used for varieties of infections and age groups. Subclinical use of the drug results in emergence of antimicrobial resistance and reduces the likelihood of having effective therapeutic outcomes whereas, over dose results in toxicological concerns. Therefore, optimal dose has to be used for better therapeutic outcomes ${ }^{16,20}$. In this study, about $94.74 \%$ of medical records had correct doses of crystalline penicillin and the rest $5.26 \%$ of cases were associated with over dose practices assuming that there was no dose adjustment despite the presence of underlying clinical conditions. Unfortunately, there were no under dosing of crystalline penicillin identified at pediatric ward of HFSUH. Generally, the overall use of dosage was found very close to the threshold $(95 \%){ }^{4,16}$. In this study, the use of crystalline penicillin when evaluated with regard to dose $(94.74 \%)$ and dose frequency $(98.14 \%)$ was found to be appropriate (on average, 96.29\%) which is in line with WHO DUE guideline and STG of Ethiopia ${ }^{4,15,16}$. In a study conducted at Jimma University specialized hospital (JUSH), the frequency of administration (100\%) was found above the expected threshold (95\%); however, the appropriateness of dosage prescribing $(81.42 \%)$ was somewhat lower than the threshold $(95 \%)$ $15,16,19$. Averagely, doses and frequency given during the study at JUSH was 50,000 IU/kg every 4-6 hrs, but differ for various diseases ${ }^{19}$.

The duration of treatment of crystalline penicillin is concerned; drug resistance has become a great problem associated with premature discontinuation of therapy or shorter drug regimen than expected for the particular clinical condition. On the other way round, prolonged use of crystalline penicillin can also lead to emergence of antimicrobial drug resistance. Besides, long duration therapy may also cause normal flora to be affected and hence foreign infections easily develop resistance. Therefore, it should be used properly according to STGs. Inappropriate duration of therapy was the major problem revealed by this study. About $13.16 \%$ cards had unspecified duration of therapy and $35.09 \%$ had less than 3 days duration of therapy. Only $51.75 \%$ cards contain crystalline penicillin prescribed with appropriate duration of therapy, which is very far from the threshold set by the guideline $(90 \%)^{15,16}$.

Compared with the present finding, better duration of therapy of crystalline penicillin was found in pediatric wards of JUSH $(83.6 \%)^{19}$. Different results were reported from study done in Chandigarh, India on Penicillin and gentamicin therapy versus Amoxicillin/ Clavulanate in Severe hypoxemic pneumonia which explains that minimum duration of IV therapy was 3 days and total of 7 days ${ }^{21}$.

\section{Journal of Drug Delivery \& Therapeutics. 2017; 7(2):62-69}

In this study, the most common indication for crystalline penicillin injection was found to be severe pneumonia and community acquired pneumonia. Early diagnosis and appropriate case management by rational use of antibiotics remains one of the most effective interventions to reduce pneumonia-related mortality. As per the UNICEF/WHO report on pneumonia "estimates suggest that if antibiotic treatment were universally delivered to children with pneumonia, around 600,000 lives could be saved each year ${ }^{22}$. According to the some guidelines, all children diagnosed as severe pneumonia needs to be hospitalized for detailed assessment, injectable antibiotics, other supportive therapy and monitoring. Regarding choice of injectable antibiotics for in-patient treatment of severe community-acquired pneumonia; there is evidence that penicillins are superior to chloramphenicol ${ }^{23}$.

Regarding to the drug-drug interaction, the simultaneous uses of two or more drugs are recommended in specially defined situations based on pharmacologically rational use of drugs. However, selection of appropriate combinations requires an understanding of the potential for interaction between the drugs. Interactions may, otherwise, affect the patient therapeutic outcome negatively. In the study, there were no noticeable drug interactions $(100 \%)$ and hence, the results are in line with the threshold set for drug interactions with crystalline penicillin (90\%). Coming to contraindications, prescribing drugs, despite the presence of contraindication, should be avoided unless the benefits of therapy outweigh any potential risks. History of patients with known hypersensitivity reaction to crystalline penicillin and other antibiotics were not observed or documented. The result is in line with the threshold set for contra-indication for crystalline penicillin use which mandates $(100 \%$ free from contraindication). This study is in concordant with the finding from JUSH where the actual performance of being freed from drug interactions and contra-indication were found to be $98.9 \%$ and $100 \%$, respectively ${ }^{19}$.

Concerning to the clinical indication, this study identified that crystalline penicillin is incorrectly indicated for some disease which is non concordant with STG. Moreover, the purpose of treatment is empirical in majority of cases $(61.41 \%)$. This show that unknowingly resistance is going to develop to crystalline penicillin since exact pathogen is not known or confirmed by laboratory investigation in the study hospital. So, in this hospital, prescribing crystalline penicillin without confirming laboratory result can lead to the development of resistance. This finding showed that among children admitted only $51.75 \%$ shows improvement which is too far from the threshold (95\%). This result is also much lower than the finding from JUSH $(91.80 \%){ }^{19}$.

\section{Limitation}

Sufficient published studies have not obtained yet regarding the DUE of crystalline penicillin in Ethiopia. Hence, it was not possible to compare the practice of pediatrics ward of HFSUH with practice of other similar clinical settings. This finding was subjected to be discussed against the STG of Ethiopia and WHO DUE guideline. Even if, sampling was made as per JCHCAO 


\section{Abdela et al}

criteria, it is somewhat small to infer to the general population. Retrospective nature of the study had also some influence on the validity and completeness of the data for analysis and evaluation.

\section{CONCLUSION}

Crystalline penicillin utilization pattern in pediatric ward of HFSUH has fully adhered to the STG of Ethiopia for general hospitals and WHO Guideline for the majority of the parameters with regard to dose and frequency of administration, contraindications, and drug interactions as well as met the thresholds set for most of the DUE criteria. However, indication, duration and outcome of therapy were not in accordance with the guideline.

\section{Ethical consideration}

Ethical approval and permission was sought and obtained from the HFSUH chief executive officer and Medical directors to conduct the study. Since data collection was conducted by reviewing the medical

\section{REFERENCES}

1. Phillips M. S.; Gayman J. E.; Todd M. W. ASHP guidelines on medication-use evaluation. American Society of Health-system Pharmacists. American Journal of Health-System Pharmacy, 1996; 53 (16): 1953-1955.

2. Doherty Paula, et al. SHPA Standards of Practice for Drug Use Evaluation in Australian Hospitals: SHPA Committee of Specialty Practice in Drug Use Evaluation. Journal of Pharmacy Practice and Research, 2004; 34 (3):220-223.

3. The Academy of Managed Care Pharmacy's, concepts in managed care pharmacy (2008) Drug use evaluation. Alexandria. 100 North Pitt Street /Suite 400/Alexandria

4. WHO (2003) Drug and therapeutic committee-A practical guide to drug use evaluation. Drug use evaluation (Drug utilization review), 155, Geneva, Switzerland. Available at:http://www.who.int/medicines/areas/rationaluse/en/

5. WHO (1998) Promoting appropriate Drug uses in Missionary health Facilities in Cameroon-EDM Research Series No. 028. Geneva, Switzerland

6. Hecker MT, Aron DC, Patel NP, Lehmann MK, Donskey CJ. Unnecessary use of antimicrobials in hospitalized patients: current patterns of misuse with an emphasis on the antianaerobic spectrum of activity. Archives of Internal Medicine. 2003; 163(8): 972-978.

7. World Health Organization (2010) WHO model formulary for children 2010. Geneva, Switzerland. www.who.int/selection_medicines/list/WMFc_2010.pdf

8. LEE, Hyuck, et al. Evaluation of ceftriaxone utilization at multicenter study. The Korean journal of internal medicine. 2009; 24 (4): 374-380.

9. Seppälä H, Klaukka T, Vuopio-Varkila J, Muotiala A, Helenius $\mathrm{H}$, et al. The effect of changes in the consumption of macrolide antibiotics on erythromycin resistance in group A streptococci in Finland. Finnish Study Group for Antimicrobial Resistance. N Engl J Med. 1997; 337: 441-446.

10. Dirba, L.; Worku, Fikru; Girma, Tsinuel. Evaluation of prophylactic use of cotrimoxazole for people living with HIV/AIDS in Jimma University specialized hospital, South West Ethiopia. Ethio J Health Sci, 2008, 18.3: 59-64.

11. MSH/WHO. Management Sciences for Health. DAP Managing Drug Supply, 2nd edition, revised and expanded. USA, Kumarian Press, Inc., 1997:472-73.

\section{Journal of Drug Delivery \& Therapeutics. 2017; 7(2):62-69}

records of pediatric patients, there was no direct risk to study subjects for participating in the study. Therefore, informed consent was not sought from the study participants, but the confidentiality of the information was assured in such a way that no disclosure of any patient's or health care provider's name and drug product in relation to the finding.

\section{Acknowledgment}

We would like to provide a deepest gratitude and appreciation for HFSUH staffs for their kindly support.

\section{Authors' contribution}

JA, MS and ZK were involved in the conception of the original idea, helped to draft the proposal, participated in all implementation stages of the project, and write up; all authors coordinated the data collection process. MS also reviewed it critically and prepared the manuscript for publication. All authors read and approved the final version of the manuscript.
12. Academy of managed care pharmacy, Concepts in Managed Care pharmacy: drug use evaluation. 1998. Available at: http://depts.washington.edu/exphasmed. Accessed Jan 2016.

13. Central statistic agency (CSA), Ethiopia, 2015. https://www.citypopulation.de/ethiopia.html

14. Joint Commission on Accreditation of Health care Organizations and National Committee for Quality Assurance, Health Care at the Crossroads: Development of a National Performance Measurement Data Strategy, 2008. https://www.jointcommission.org/

15. WHO (2005) Pocket book of hospital care for children Guidelines for the management of common illnesses with limited resources. Geneva, Switzerland.

16. Food, Medicine and Health Care Administration and Control Authority (FMHACA), Standard Treatment Guideline for General Hospitals. $3^{\text {rd }}$ edition, 2014, Addis Ababa, Ethiopia.

17. Daniel P. Raymond, MD, Shawn J. Pelletier, MD, Robert G. Sawyer, MD (Antibiotic Utilization Strategies to Limit Antimicrobial Resistance, Semin Respir Crit Care Med. 2002; 23(5)

18. CDC (2013) centers for Disease Control and Prevention: Core Elements of Hospital Antibiotic Stewardship Programs : available at:- https://www.cdc.gov/

19. Siraj J, Ahmed SM, Evaluation of Crystalline Penicillin Use in Pediatrics Ward of Jimma University Specialized Hospital, South West Ethiopia. Clin Exp Pharmacol. 2013; 3:135. doi:10.4172/2161-1459.1000135

20. Henry F. Chambers. General considerations of antimicrobial therapy. I: Laurence. Burtol, Jones, Keithl, Parker; Goodman and Gilman's pharmacologic basis of therapeutics. $11^{\text {th }} \mathrm{Ed}$. New york: MCGraw- HILL; 2006: 1095-1119.

21. Gould IM, Jappy B. Trends in hospital antimicrobial prescribing after 9 years of stewardshipJ Antimicrob Chemother. 2000; 45 (6): 913-917

22. UNICEF. Pneumonia: The Forgotten Killer of Children. The United Nations Children's Fund (UNICEF)/WHO, 2006. http://www.unicef.org/publications/files/Pneumonia_The_Forg otten_Killer_of_Children.pdf.

23. Kabra SK, Lodha R, Pandey RM. Antibiotics for community acquired pneumonia in children. Cochrane Database Syst Rev 2006; 3: CD004874. 